\title{
Study on Effect of Rainfall on Earth Pressure of Shield Tunnel in Expansive Soil Stratum
}

\author{
CHAO Feng ${ }^{1,2, a}$, YAO Zaifeng ${ }^{2, b}$, GUO Xiaohong ${ }^{2, c}$ \\ ${ }^{1}$ College of Civil Architecture and Engineering, Beijing Jiaotong University, China \\ 2 Technical Center of China State Construction Engineering Corporation, China \\ afengchao0217@163.com, b498778959@qq.com, c974850392@qq.com
}

Keywords: expansive soil; earth pressure of shield tunnel; rainfall; strength reduction; additional expansive stress field

Abstract. Strength reduction and expansion deformation of expansive soil would happen due to change of moisture content. Effect of rainfall on earth pressure of shield tunnel in expansive soil stratum is studied by taken reduction of expansive soil strength and additional expansive stress field into consideration. Vertical earth pressure caused by strength reduction decreases with increasing depth, and value change is less than $3 \mathrm{kPa}$ when depth exceeds $20 \mathrm{~m}$. Vertical earth pressure caused by additional expansive stress field is less than $10 \mathrm{kPa}$ and influence range is mainly in the upper part of segment ring. Recommended values of earth pressure caused by rainfall is proposed when depth less than $6 \mathrm{~m}$.

\section{Introduction}

With the rapid development of urban rail transit in China, in the end of 2015, the mileage of urban rail transit lines in China reached more than $3,200 \mathrm{~km}$. There is a vast territory in our country, and the construction environment of urban rail transit is also varied. Typical stratums include sand-gravel stratum and loess stratum, hard and soft strata, etc. There are few researches on the urban rail transit shield tunnel in the expansive soil strata, at present. Typical areas have a wide range of expansive soil distributions, Hefei, Nanning and Chengdu are included.

In recent years, the economic loss that caused by expansive soil is estimated to be more than 15 billion U.S. dollars in China [1,2]. The characteristics of expansive soils are characterized by strength, deformation and fracture [3]. Many experts and scholars has made many achievements and successful engineering experience by carrying out a lot of theoretical analysis, technical research and engineering practice based on the expansive land layer slope, roadbed, structures and other projects. However, there are few studies on the subsurface structure of expansive soil layer.

The seepage equation of isotropic unsaturated soil is:

$$
\frac{\partial}{\partial x}\left(\mathrm{k}_{w} \frac{\partial h}{\partial x}\right)+\frac{\partial}{\partial y}\left(\mathrm{k}_{w} \frac{\partial h}{\partial y}\right)+\frac{\partial}{\partial z}\left(\mathrm{k}_{w} \frac{\partial h}{\partial z}\right)=n \frac{\partial S_{w}}{\partial t}+S_{w} S_{s} \frac{\partial h}{\partial t}
$$

Where, $k_{w}$ is the permeability coefficient, $S_{w}$ is the saturation, $S_{s}$ is the unit of storage, $h$ is the head height.

The condition of the water content above the seepage free surface is governed by unsaturated flow. Rainfall or irrigation water infiltration underground are usually unsaturated seepage. Neuman proposed to consider both the saturation and non-saturation mathematical model [4].

This equation can be replaced by pressure head $p$ instead of head $h$, with volumetric moisture content $n_{w}$ instead of saturation $S_{w}$; and the unit capacity of water $C=\frac{\partial n_{w}}{\partial p}$, formula (1) can be written as:

$$
\frac{\partial}{\partial x}\left(k_{w} \frac{\partial p}{\partial x}\right)+\frac{\partial}{\partial y}\left(k_{w} \frac{\partial p}{\partial y}\right)+\frac{\partial}{\partial z}\left(k_{w} \frac{\partial p}{\partial z}\right)+\frac{\partial k_{w}}{\partial z}=\left(C+\frac{n_{w}}{n} S_{s}\right) \frac{\partial p}{\partial t}
$$

Formula (2) can be solved by using the initial conditions and boundary conditions. The free surface of seepage can be connected by the point where $p=0$. 


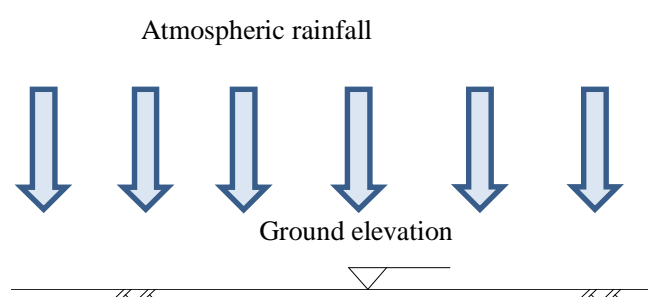

Groundwater level 1

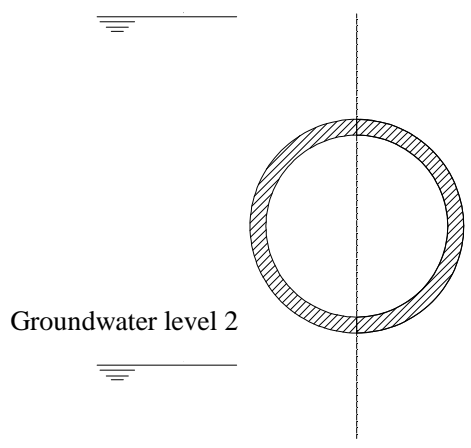

Fig .1 Schematic diagram of effect of rainfall on earth pressure of shield tunnel in expansive soil stratum

As shown in Figure 1, rainfall will cause the reduction of soil strength parameters and the expansion of soil. This paper studies the change of formation earth pressure under the condition of rainfall with the shield tunnel of expansive soil layer in Hefei area, which is instructive for the design of shield tunnel in expansive soil layer.

\section{The Influence Range of Rainfall on Stratum Water Content in Hefei Area}

\section{Characteristics of expansive soil in Hefei area}

Strength characteristics. The relationship between shear strength parameters $c, \varphi$ and water content of expansive soil in Hefei area is as follows:

$$
\left.\begin{array}{l}
c=a_{1} e^{b_{1} \omega} \\
\phi=a_{2} e^{b_{2} \omega}
\end{array}\right\}
$$

In the formula, $a_{1}, b_{1}, a_{2}, b_{2}$ are the fitting coefficients, and the values can be determined with reference to [5] or through experiments. Under the premise of knowing the change of water content, the strength parameters of different water content can be calculated according to the above empirical formula, and the strength parameters of the soil layer can be reduced.

The shear strength and moisture content of the soil are exponentially related to each other. With the increase of the moisture content, the shear strength suddenly decreases and then gradually decreases. Compared with the peak value, the cohesion value is reduced by about $70 \%$ and the internal friction angle is reduced by about $55 \%$.

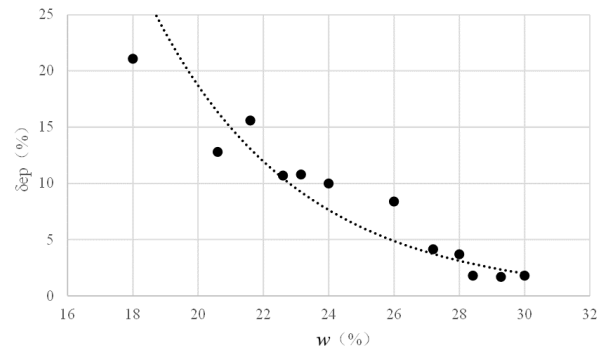

Fig.2 Curve of expansion ratio vs initial moisture content

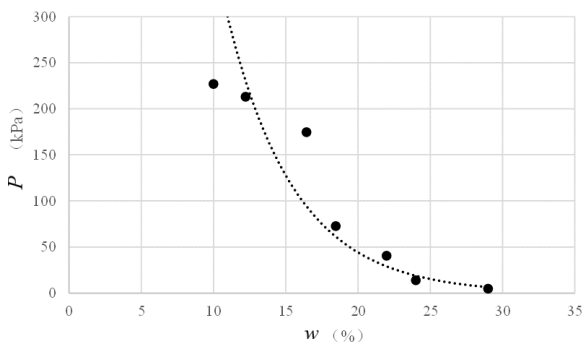

Fig.3 Curve of expansion force vs initial moisture content 
Swelling characteristics. The curve of the relationship between the expansion rate and the initial moisture content of expansive soil in of Hefei Feixi area is shown in Fig. 2 [6], which shows that expansion rate of the soil increases with the decrease of the initial water content, and the two approximate the exponential function relationship. The relationship between the expansion force and the initial moisture content in the Hefei area is shown in Fig. 3, which shows that with the increase of the initial moisture content, the expansion force gradually decreases, and the relationship between the two is approximately linear.

\section{Formation moisture content influenced by rainfall}

A numerical model of $20 \mathrm{~m} \times 20 \mathrm{~m} \times 20 \mathrm{~m}$ was built using FLAC3D software which is shown in Fig. 4 . The formation parameters are shown in Tab. 1. The maximum monthly rainfall in Hefei is selected to simulate precipitation infiltration. The discharge is imposed on the upper boundary, and the boundary assumes full penetration of the rainfall during calculation process. The result of the calculation is shown in Fig. 5.

Tab.1 Soil parameters

\begin{tabular}{|c|c|c|c|c|c|c|c|c|c|}
\hline Stratum & $\gamma / \mathrm{KN} \cdot \mathrm{m}^{-3}$ & $c / \mathrm{KPa}$ & $\varphi /^{\circ}$ & $E / \mathrm{MPa}$ & $v$ & $\omega$ & $\mathrm{e}$ & $\delta_{e f}(\%)$ & $P_{e}(\mathrm{kPa})$ \\
\hline Clay layers(2) & 20 & 47 & 12 & 8.91 & 0.3 & $20.6 \%$ & 0.69 & 55 & 60 \\
\hline
\end{tabular}
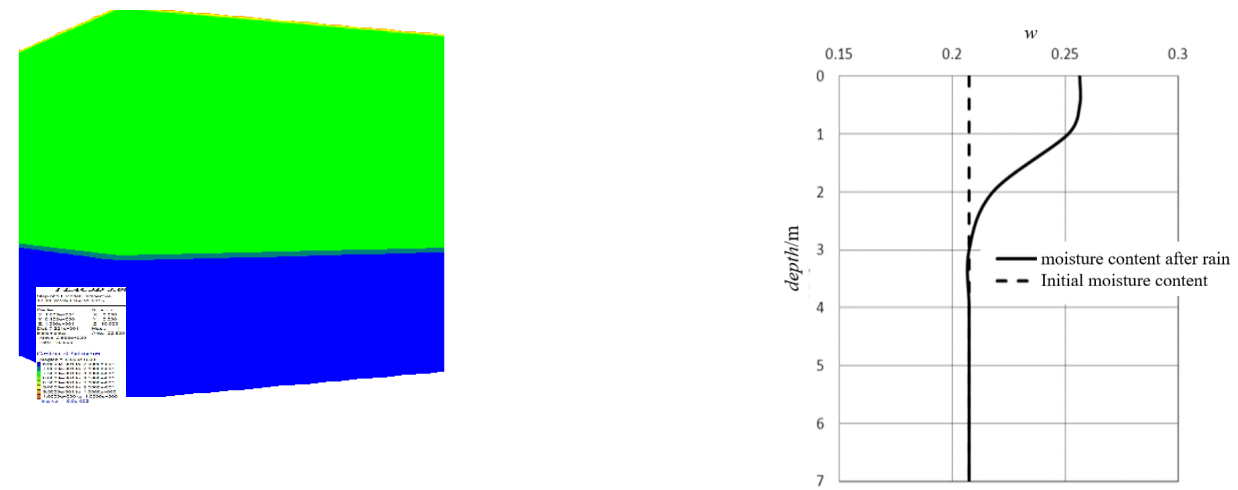

Fig .4 Computational model of rainfall infiltration Fig .5 Distribution of moisture content after rainfall

The impact of rainfall on expansive soil in Hefei area is about $3 \mathrm{~m}$, and the depth of saturated area is about $0.8 \mathrm{~m}$, based on Fig. 10 . The moisture content distribution in the transition zone and the conduction zone is approximately linear. According to the general burial depth of urban rail transit underground structures, shield tunnel effected by rainfall is only under certain depth conditions which generally buried deeper than double the tunnel diameter(1D).

\section{Effect of rainfall on earth pressure of shield tunnel in expansive soil Stratum}

Values of $c, \varphi$ reduced and additional stress field of expansive soil generated by changes of moisture content of expansive soil stratum during rainfall, which will cause influences to the earth pressure of shield tunnel.

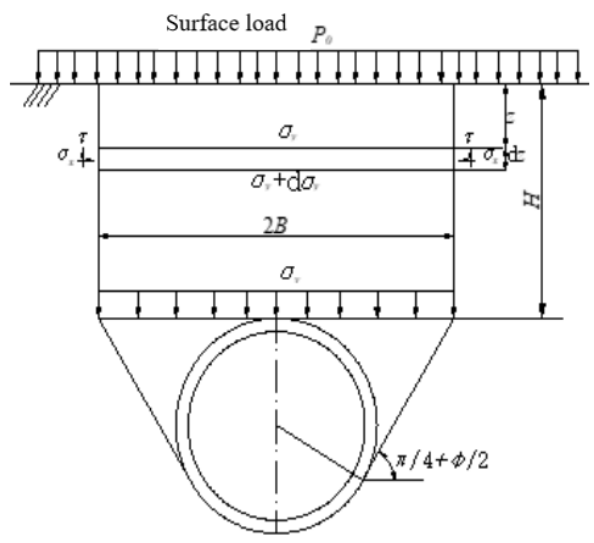

Fig .6 Schematic diagram of Terzaghi relaxation earth pressure 
Effect of Reduction of Soil Parameters on Vertical Earth Pressure. Vertical earth pressure of segment can be calculated by Terzaghi relaxation earth pressure which in a uniform formation. Take a circular tunnel as an example, Terzaghi relaxation earth pressure is shown in Fig. 6, which is obtained by the force balance in the vertical direction of the soil which slides downward caused by tunnel excavation, where an active sliding surface created between sides and top of the tunnel[9]. The formula is shown as follows:

$$
\begin{gathered}
\sigma_{v}=\frac{B(\gamma-c \mid B)}{K \cdot \tan \varphi}\left(1-e^{-K \cdot \tan \varphi \cdot H / B}\right)+P_{0} e^{-K \cdot \tan \varphi \cdot H / B}, \\
B=R \times \cot \left(\frac{\pi / 4+\varphi / 2}{2}\right)
\end{gathered}
$$

In the formula, $\gamma$ is soil weight; $R$ is tunnel radius; $\varphi$ is internal friction angle; $c$ is cohesion; $H$ is tunnel depth; $B$ is half of the width of the tunnel excavation; $K$ is soil side pressure coefficient.

Schematic diagram of vertical earth pressure on vault is shown in Fig. 7, when rainfall occurs on the surface.

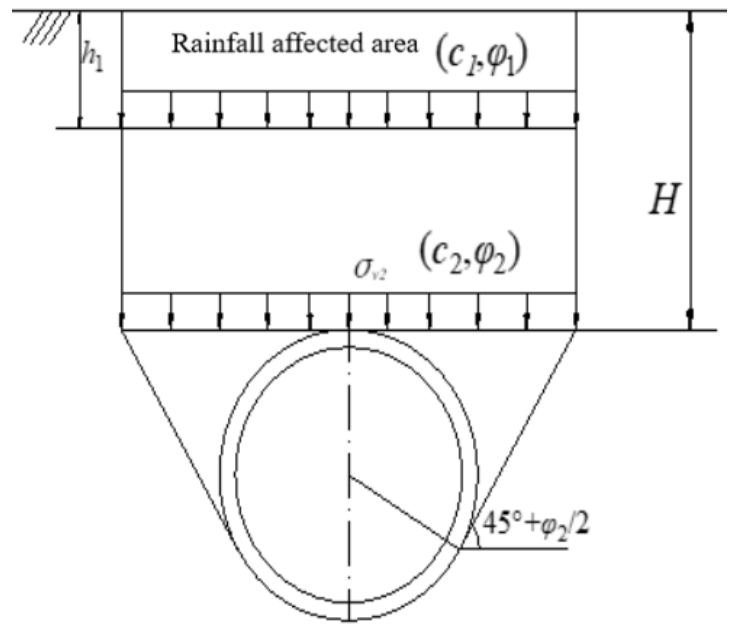

Fig .7 Schematic diagram of vertical earth pressure affected by rainfall

The effect of rainfall on vertical earth pressure can be calculated in accordance with the stratified layer load calculation method.

$$
\begin{gathered}
\sigma_{v 1}=\frac{B_{2}\left(\gamma_{1}-C_{1} / B_{2}\right)}{K \cdot \tan \varphi_{1}}\left(1-e^{-K \cdot \tan \varphi_{1} \cdot H_{1} / B_{2}}\right) \\
\sigma_{v 2}=\frac{B_{2}\left(\gamma_{2}-C_{2} / B_{2}\right)}{K \cdot \tan \varphi_{2}}\left(1-e^{-K \cdot \tan \varphi_{2} \cdot H_{2} / B_{2}}\right)+\sigma_{v 1} e^{-K \cdot \tan \varphi_{2} \cdot H_{2} / B_{2}}
\end{gathered}
$$

In the formula, $c_{1}, \varphi_{1}$ are cohesion and internal friction angle of soil in rainfall-affected zone. $c_{2}, \varphi_{2}$ are cohesion and internal friction angle of soil in non-rainfall-affected zone.

According to Eq. 3 and Eq. 7, vertical earth pressure of segment effected by soil mechanics parameters reduction is shown in Fig. 8, when rainfall occurs on the surface. With the increase of burial depth, vertical earth pressure of segment influenced by soil mechanics parameters reduction decreases. Variation of earth pressure is less than $3 \mathrm{kPa}$, when the burial depth is greater than $20 \mathrm{~m}$, which is considered to have no effect. 


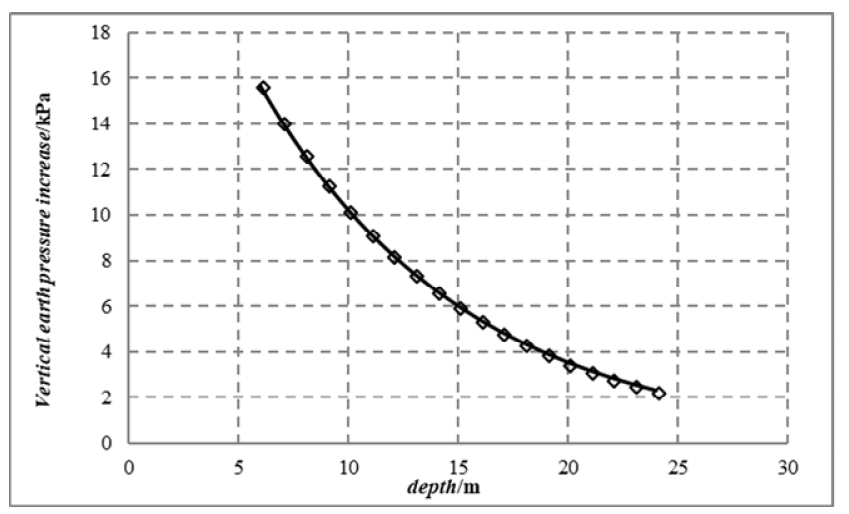

Fig .8 Vertical earth pressure of segment effected by soil mechanics parameters reduction Influence of Additional Stress Field of Expansive Soil on Earth Pressure. The impact of surface rainfall on formation moisture content is mainly within $3 \sim 4 \mathrm{~m}$ below the surface in Hefei area. Computational models with burial depths of $3 \mathrm{~m}, 4 \mathrm{~m}, 5 \mathrm{~m}$, and $6 \mathrm{~m}$ were established to calculate and analyze the effect of shield load in expansive soil layer under rainfall conditions, which calculation parameters refer to the values in Tab. 1. An equivalent expansion stress field is applied in the range of $3 \mathrm{~m}$ above the surface which affected by rainfall, shown in Fig. 9 .

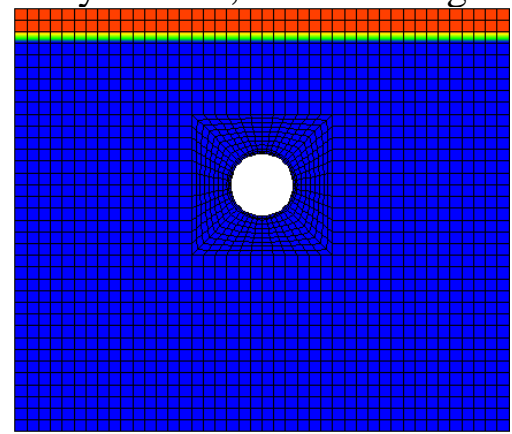

Fig .9 Computational model of rainfall

Tab.2 Additional earth pressure results caused by rainfall

\begin{tabular}{|c|c|c|c|c|}
\hline \multirow{2}{*}{ depth/m } & \multicolumn{4}{|c|}{ Additional earth pressure $/ \mathrm{kPa}$} \\
\cline { 2 - 5 } & vault & Spandrel & Arched foot & Invert \\
\hline 3 & 9.70 & 3.94 & 0.95 & -1.92 \\
\hline 4 & 9.41 & 4.46 & 1.05 & -2.21 \\
\hline 5 & 7.47 & 4.33 & 0.72 & -1.60 \\
\hline 6 & 7.75 & 3.84 & 0.34 & -0.87 \\
\hline
\end{tabular}

The calculation results are shown in Table 2.The additional stress field of expansive soil caused by rainfall has little influence on shield segment load in expansive soil stratum, which is less than $10 \mathrm{kPa}$ in Hefei area and focused on the upper part of segment. Additional earth pressure of the segment under rainfall conditions can be calculated according to Table 2 when the depth of burial is less than $6 \mathrm{~m}$ and can be ignored when the burial depth is greater than $6 \mathrm{~m}$.

\section{Conclusions}

(1)Shear strength and moisture content of the soil are exponentially related to each other. Expansion force and expansion deformation can be considered as an approximately linear relationship within a certain range of water content variation.

(2) Impact of rainfall on expansive soil in Hefei area is about $3 \mathrm{~m}$, and the depth of saturated area is about $0.8 \mathrm{~m}$. The moisture content distribution in the transition zone and the conduction zone is approximately linear. With the increase of burial depth, vertical earth pressure of segment influenced by soil mechanics parameters reduction decreases, which is less than $3 \mathrm{kPa}$.

(3) Additional stress field of expansive soil caused by rainfall has little influence on shield segment load in expansive soil stratum, which is less than $10 \mathrm{kPa}$ in Hefei area and focused on the upper part of 
segment. Additional earth pressure of the segment under rainfall conditions can be calculated according to Table 2 when the depth of burial is less than $6 \mathrm{~m}$ and can be ignored when the burial depth is greater than $6 \mathrm{~m}$.

\section{References}

[1]Liu Tehong. Expansive Soil Problems in Engineering Construction [M]. China Building Industry Press, 1997.

[2]Liao Shiwen. Expansive Soil and Railway Engineering [M]. China Railway Press, 1984.

[3]Zheng Jian-long. Theory and Technology for Highway Expansive Soil Engineering[M]. Beijing: China Communications Press, 2013.

[4]NEUMAN S P. Saturated-unsaturated seepage by finite elements[J]. Proc ASCE HY, 1973,97(12):2233-2250.

[5]Liu Yang. The Relationship between Shear Strength and Water Content of Hefei Expansive Soil and its Engineering Applying [D]. Hefei University of Technology, 2003.

[6]Jiang Xiao-qing. The Trial Research on Basic Mechanical Properties of Expansive soils in Hefei [D]. Anhui University of Architecture, 2010.

[7]Yao Hai-lin, Zheng Shao-he, Li Wen-bin, et al. Parametric Study on the Effect of rain infiltration on Stability of Unsaturated Expansive Soil Slope[J]. Chinese Journal of Rock Mechanics and Engineering, 2002(07):1034-1039.

[8]Chen Shan-xiong, Chen Shou-yi. Analysis of Stability of Unsaturated Soil Slope due to Permeation of Rainwater [J]. Rock and Soil Mechanics, 2001(04):447-450.

[9]TERZAGHI K. Stress Distribution In Dry And In Saturated Sand Above A Yielding Trap-door: Proceedings Of First International Conference On Soil Mechanics And Foundation Engineering. Cambridge, Massachusetts, Cambridge, Massachusetts, 1936[C]. 